\title{
Ex vivo DNA assembly
}

\section{Adam B. Fisher ${ }^{1}$, Zachary B. Canfield ${ }^{2}$, Laura C. Hayward ${ }^{2}$, Stephen S. Fong ${ }^{1,2 *}$ and George H. McArthur IV ${ }^{2}$ *}

1 Integrative Life Sciences Program, Virginia Commonwealth University, Richmond, VA, USA

${ }^{2}$ Department of Chemical and Life Science Engineering, Virginia Commonwealth University, Richmond, VA, USA

Edited by:

Zhanglin Lin, Tsinghua University,

China

Reviewed by:

Weiwen Zhang, Tianjin University,

China

Mario Andrea Marchisio, Harbin

Institute of Technology, China

*Correspondence:

Stephen S. Fong and

George H. McArthur IV, Department

of Chemical and Life Science

Engineering, Virginia Commonwealth

University, 601 West Main Street,

Richmond, VA 23284-3028, USA

e-mail: ssfong@vcu.edu;

mcarthurgh@vcu.edu
Even with decreasing DNA synthesis costs there remains a need for inexpensive, rapid, and reliable methods for assembling synthetic DNA into larger constructs or combinatorial libraries. Advances in cloning techniques have resulted in powerful in vitro and in vivo assembly of DNA. However, monetary and time costs have limited these approaches. Here, we report an ex vivo DNA assembly method that uses cellular lysates derived from a commonly used laboratory strain of Escherichia coli for joining double-stranded DNA with short end homologies embedded within inexpensive primers. This method concurrently shortens the time and decreases costs associated with current DNA assembly methods.

\author{
Keywords: DNA assembly, ex vivo, end joining, cellular lysates, colorimetric screen, synthetic biology, genetic \\ engineering
}

\section{INTRODUCTION}

Our capacity to (re)engineer living systems is linked to our ability to physically build specific DNA molecules that encode desired functionality and behavior. Traditionally, recombinant DNA has been constructed using restriction cloning (i.e., cutting with an endonuclease and joining with a ligase). In addition to restrictionligation approaches, site-specific recombination systems have been employed to assemble DNA with great success (Hartley et al., 2000). However, genetic engineering has recently become more flexible with the use of sequence-independent approaches that take advantage of the decreasing cost of DNA synthesis (Li and Elledge, 2007; Gibson et al., 2009; Quan and Tian, 2009, 2011; Zhang et al., 2012). For example, a completely synthetic Mycoplasma genome was assembled from chemically synthesized double-stranded DNA (dsDNA) fragments (5-7 kbp each) using an in vitro chew-back assembly method in 2008 (Gibson et al., 2008). The authors report that the assembled half-genome DNA molecules could not be propagated by $E$. coli due to their size and therefore relied on yeast transformation-associated recombination (TAR), an in vivo assembly in Saccharomyces cerevisiae, to finish constructing the genome (Ma et al., 2002). More recently, the mouse mitochondrial genome was reconstructed from overlapping synthetic singlestranded oligonucleotides (60 nucleotides each) using a threeenzyme in vitro isothermal DNA assembly method (ISO assembly, also known as Gibson assembly) (Smith et al., 2010).

These homology-based approaches are extremely versatile, but there are disadvantages associated with each. Although isothermal DNA assembly provides a quick and reliable way to simultaneously join together multiple pieces of DNA, the cost of the purified enzymes needed to carry out the assembly reaction is non-trivial ( US $\$ 3 /$ reaction formulated in-house). TAR cloning in S. cerevisiae is considerably cheaper but requires: (1) preparation of yeast spheroplasts, (2) the inclusion of both a selection marker and replication origin that function in yeast, and (3) the subsequent purification of the assembled DNA product (if the DNA is intended to be used in an organism other than yeast). This is a long process that takes 8-9 days to complete (Gibson et al., 2008). To address the monetary cost of ISO assembly and the time cost of TAR cloning, we hypothesized that the DNA repair machinery endogenous to yeast and other microorganisms would remain functional within cellular lysates and should be able to catalyze the assembly of linear and circular DNA constructs in just hours.

We tested this hypothesis using cellular lysates derived from $S$. cerevisiae, E. coli, and Deinococcus radiodurans, an extremophilic bacterium known to have exceedingly efficient dsDNA repair capabilities. The overall goal of this study was to determine if this general lysate-based approach, termed ex vivo DNA assembly, is feasible for physically joining DNA molecules quickly, cheaply, and efficiently. The ex vivo assembly reactions were characterized by gel electrophoresis analysis and by a colorimetric screen of the resulting E. coli transformants (in which colonies housing the correctly assembled plasmid express a vibrant blue chromoprotein). Here we demonstrate that ex vivo dsDNA assembly is organismdependent (E. coli lysate is able to perform end joining, but lysate derived from S. cerevisiae or D. radiodurans is not) and we show that in vivo circularization of overlapping dsDNA occurs after transformation in E. coli, a process that is often overlooked when characterizing in vitro DNA assembly methods.

\section{RESULTS}

To assess the ability of select cellular lysates to join together dsDNA, we first designed two amplicons with appropriate overlapping ends (26 and $30 \mathrm{bp}$ overlaps) to be assembled into a circular plasmid (Figure 1A). Correctly assembled plasmids endow $E$. 


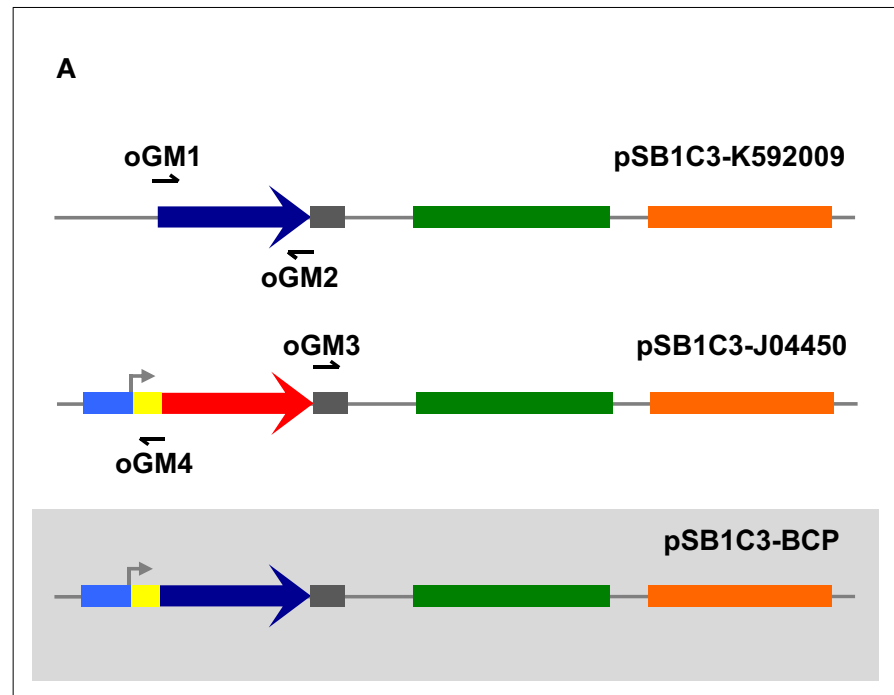

FIGURE 1 | Two-way ex vivo circular DNA assembly. Two-way assembly was demonstrated by joining a coding sequence for blue chromogenic protein (a 669 bp segment of pSB1C3-K592009 (colored in dark blue) amplified using primers oGM1 and oGM2) and the majority of pSB1C3-J04450 (a 2419 bp segment amplified by primers oGM3 and

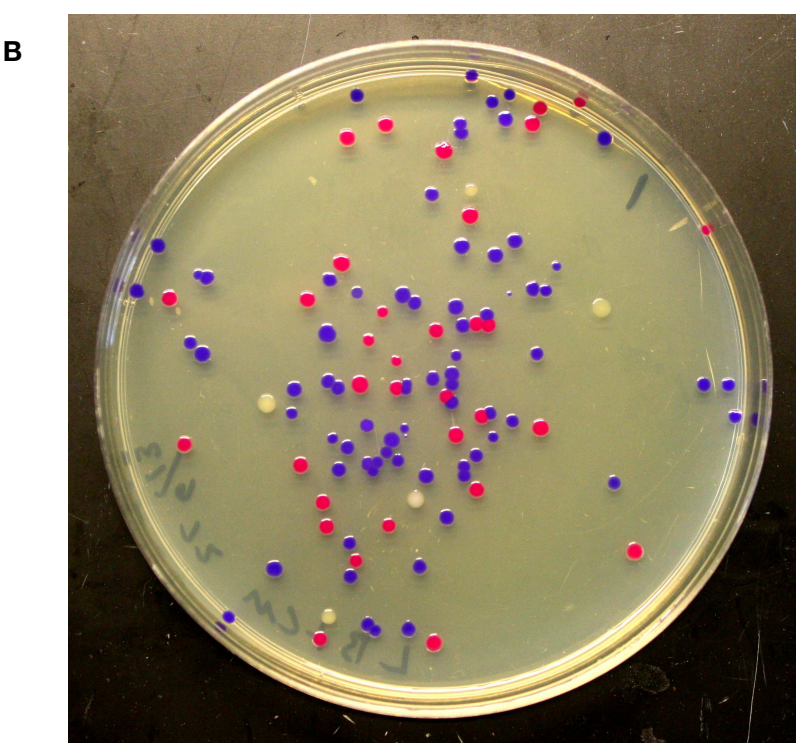

oGM4), thereby replacing RFP with BCP in pSB1C3-BCP (A). The pMB1 replication origin is colored in green and the chloramphenicol resistance gene is colored orange. Correctly assembled plasmids allow transformants to express BCP (blue colonies) while colonies containing carryover template plasmids appear either red or white (B) coli transformants with selective resistance to the antibiotic chloramphenicol and also visually screenable expression of a blue chromogenic protein (BCP) native to the coral Acropora millepora (Figure 1B) (Alieva et al., 2008). Template plasmids housing the $b c p$ coding sequence (pSB1C3-K592009) and the appropriate antibiotic resistance and replication origin (pSB1C3-J04450) produce white and red/pink colonies, respectively, providing a convenient way to track transformation efficiencies (Figure 1B). In this initial experiment, we used lysates of S. cerevisiae, E. coli, and $D$. radiodurans (hereafter $S c e, E c o$, and Dra, respectively) and a simple buffer containing ATP and $\mathrm{MgCl}_{2}$ to attempt ex vivo DNA assembly. The two amplicons were incubated for $1 \mathrm{~h}$ with each lysate. Samples of each reaction mixture were subsequently used to transform E. coli NEB10 $\beta$.

Interestingly, Dra-incubated DNA did not produce transformants, although DNA incubated with Sce or Eco successfully transformed E. coli. Further analysis by agarose gel electrophoresis showed significant degradation of the individual amplicons, indicating that a highly active exonuclease system might have prevented the assembly of DNA by Dra (Figure S1 in Supplementary Material). Even expected background transformants resulting from lingering circular PCR template were absent, suggesting that endonuclease activity is also high in Dra. Indeed, after further investigation we found a consensus $\operatorname{DrdI}$ site (GAC-N 6 -GTC) between 1475 and 1486 (GACGCTCAAGTC) in the replication origin of our plasmids (Polisson and Morgan, 1989).

We then explored ways to improve the efficiency of ex vivo DNA assembly with Eco and Sce by varying the relative composition of ATP and $\mathrm{MgCl}_{2}$ in our buffer, adding NAD to the buffer to power $\mathrm{NAD}^{+}$-dependent processes such as ligation, modulating the temperature at which the reaction mixture was incubated, increasing the amount of cellular lysate in our reaction, and increasing the duration of incubation. To directly assess the efficacy of ex vivo DNA assembly and avoid variation associated with transformation, we chose to visualize formation of a linear product (Figure 2A) from a pair of overlapping amplicons (28 bp overlap) via agarose gel electrophoresis of the ex vivo assembly reaction prior to transformation (Figure $2 \mathbf{B}$ ). In this manner, we were able to compare different reaction conditions on their ability to join two overlapping dsDNA into one linear product.

Buffers were made of $1 \mathrm{mM}$ DTT, $1 \mathrm{mM}$ NAD, and varying concentrations of ATP and $\mathrm{Mg}^{2+}$. A wide range of ATP: $\mathrm{Mg}^{2+}$ ratios were initially tested with $1-\mathrm{h}$ Eco reactions at $37^{\circ} \mathrm{C}: 1: 5,1: 10$, $1: 20,5: 5,5: 10,5: 20,10: 5,10: 10$, and 10:20 (mM:mM). Only three ATP: $\mathrm{Mg}^{2+}$ ratios were chosen for further reaction optimization: 10:5, 5:5, and 1:10 (mM:mM), buffers $1-3$ in Figure 2B, respectively). Linear products resulting from assembly by Sce were not at all visible in the gel, although bands of small pieces of DNA indicate that there is some nuclease activity under most conditions tested. On the other hand, Eco appears to have significant activity at 30 and $37^{\circ} \mathrm{C}$ even without the addition of buffer. Previous studies have noted that the nucleolytic behavior of the RecBCD complex of $E$. coli changes based upon the relative amount of ATP to free $\mathrm{Mg}^{2+}$ in vitro (Taylor and Smith, 1995). We observed a similar trend in our lysates; the most efficient assembly reactions (for both 30 and $37^{\circ} \mathrm{C}$ ) were carried out under conditions of excess magnesium relative to ATP (Buffer 3 in Figure 2B), probably because ATP can chelate $\mathrm{Mg}^{2+}$ with high affinity under physiological conditions (Wilson and Chin, 1991). 


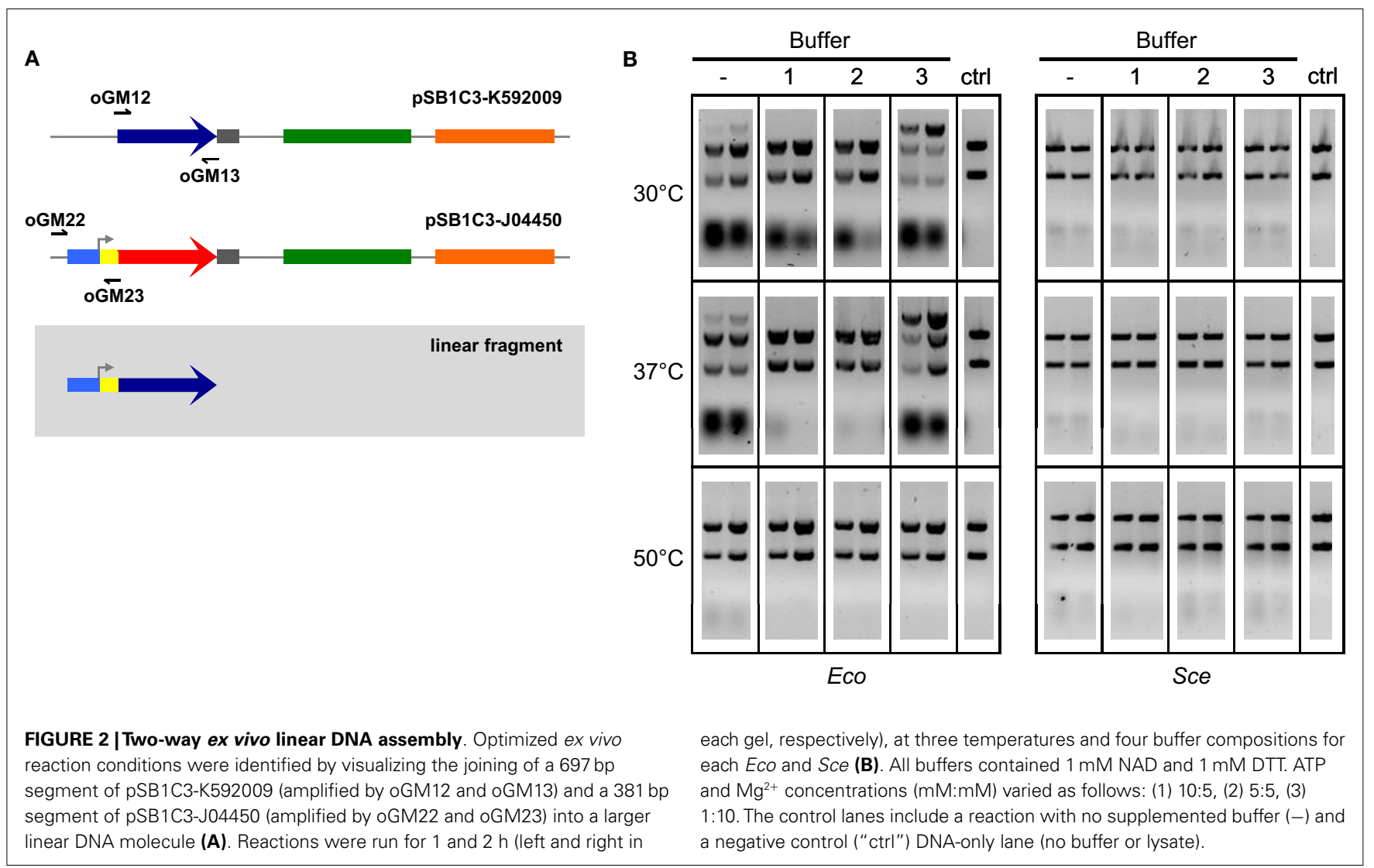

Each ex vivo reaction condition was tested for both 1- and 2-h incubations. Initial experiments indicated that greater incubation times (3-6h) do not improve ex vivo assembly yields (data not shown). For all successful assemblies, 2-h reactions appear to generate more linear product than 1-h reactions. The temperatures selected for ex vivo reaction optimization reflect cell culture conditions $\left(30^{\circ} \mathrm{C}\right.$ for yeast and $37^{\circ} \mathrm{C}$ for $\mathrm{E}$. coli) and the temperature used for ISO assembly reactions $\left(50^{\circ} \mathrm{C}\right)$. The $50^{\circ} \mathrm{C}$ reactions are considered a negative control since we do not expect the cellular machinery in Eco or Sce to be thermostable, although transient activity may occur initially. Based on the results of these experiments we selected a buffer composition of $1 \mathrm{mM}$ ATP, $10 \mathrm{mM}$ $\mathrm{Mg}^{2+}, 1 \mathrm{mM}$ DTT, and $1 \mathrm{mM} \mathrm{NAD}{ }^{+}$(i.e., Buffer 3 in Figure 2B) incubated at $37^{\circ} \mathrm{C}$ for $2 \mathrm{~h}$ as our optimized conditions for both $E c o$ and Sce.

Under optimized reaction conditions, Eco and Sce were used again to perform the two-way dsDNA assembly. In addition, we designed three overlapping amplicons $(30,29$, and $26 \mathrm{bp}$ overlaps) to demonstrate a three-way assembly, which is not only more complex but also more useful for generating combinatorial libraries (Figure 3A). For each of these assembly tests, lysate-incubated DNA was allowed to react for $2 \mathrm{~h}$ before transformation of E. coli. Control conditions of zero incubation time and reactions with no lysate added were also run to ensure that the lysate was indeed facilitating DNA assembly and not otherwise affecting the transformation process.
Our results (Figures 3B and 3C) clearly indicate that DNA is indeed being assembled ex vivo. For two- and three-way assemblies, both Eco and Sce, transformation efficiencies significantly increase when the DNA to be assembled is allowed to incubate with the lysate. Unexpectedly, the "no lysate" negative control revealed that for two- and three-way assemblies the overlapping amplicons can be joined together into a circular plasmid in vivo, suggesting that a significant fraction of the ex vivo assembly reactions and also in vitro reactions (e.g., ISO assembly) - actually occur inside E. coli after transformation (i.e., TAR cloning in E. coli). Although Eco-mediated assembly produced many blue colonies for both two- and three-way assemblies (423 and 491 colonies, respectively), Eco appeared to be detrimental to the overall transformation efficiency when it was not allowed to incubate with the DNA amplicons.

To test whether or not the detergent-based lysis buffer used to produce Eco was affecting the transformation process, we carried out the assembly reactions and transformations in the presence of the lysis buffer but without cellular lysate. As summarized in Table S1 in Supplementary Material, the bacterial lysis buffer inhibits transformation completely. Therefore, Eco-mediated assembly is likely much more efficient than we have observed and an alternative lysis method would probably increase overall transformation efficiency. The yeast lysis buffer does not appear to inhibit transformation of E. coli, which is not surprising because it is designed to lyse yeast cells. Interestingly, the number of colonies produced by DNA incubated with yeast lysis buffer was statistically identical 


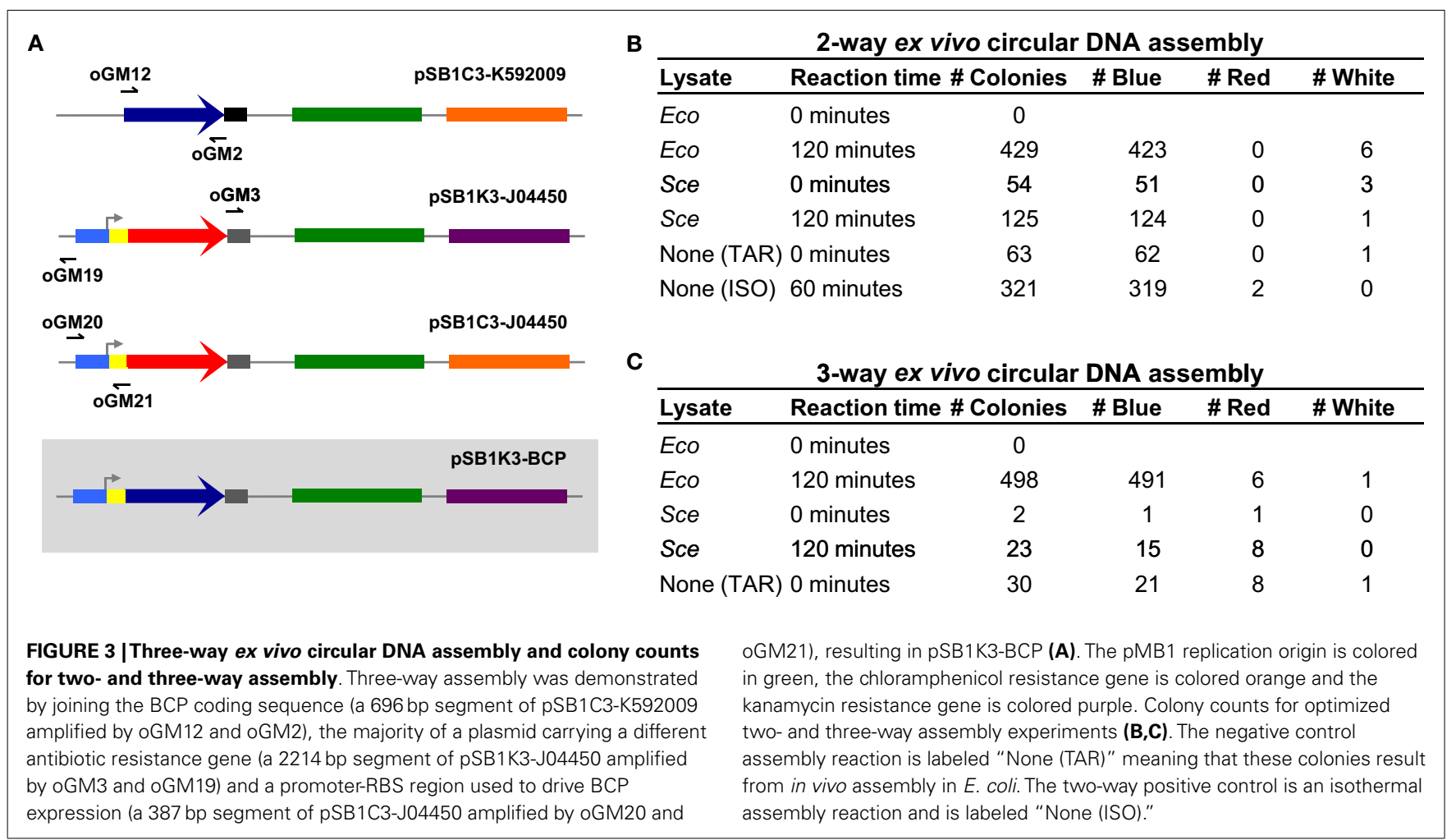

to the number of colonies produced by Sce-incubated DNA and that produced by the "no lysate" control. These data suggests that Sce-mediated DNA assembly was not observed but rather indicates that in vivo end joining in E. coli facilitates DNA assembly in this case.

\section{DISCUSSION}

The assembly of DNA sequences in novel combinations is fundamental to genetic engineering and molecular biology research. We sought to develop an inexpensive and efficient method for DNA assembly by using cellular lysates instead of purified enzymes to perform DNA end joining. Through a series of experiments investigating circular and linear DNA assembly, we found that: (1) lysate derived from E. coli NEB10 $\beta$, a RecA-deficient strain, was able to efficiently assemble dsDNA, (2) a fraction of the assembly takes places inside $E$. coli NEB10 $\beta$ post-transformation by in vivo DNA assembly, and (3) lysates derived from D. radiodurans and S. cerevisiae were not able to join together dsDNA under the conditions we tested. In addition, it is worth highlighting that we attempted single-stranded DNA (ssDNA) assembly of synthetic 60 -mer oligonucleotides (20 bp overlaps) that was accomplished by ISO assembly but was unsuccessful using our ex vivo approach (data not shown). Over the course of all of our experiments we found that the trends in efficiency of assembly held true across organisms independent of batch-to-batch variation.

To assess the efficacy of ex vivo DNA assembly, we used a combination of analytical gel electrophoresis for visualizing linear product and a novel colorimetric screen for easily identifying colonies containing assembled circular DNA. The colorimetric screen is particularly useful because it allows the simultaneous detection of desired DNA assembly (correctly assembled plasmids express BCP, making E. coli colonies appear blue/purple) and determination of transformation efficiency between trials by tracking carryover template plasmids (pSB1C3-K592009 produces typical white colonies while pSB1C3-J04450 and pSB1K3-J04450 produce red colonies by expressing mRFP1). In this case, template plasmid digestion by $D p n \mathrm{I}$ is not preferred. We anticipate that the design of similar colorimetric screens, in which individual template plasmids can either be selected against or uniquely identified by color, will assist in the development of superior DNA assembly methods and aid in the study of natural DNA repair mechanisms.

In E. coli, double-strand break (DSB) repair, dominated by homologous recombination, relies on the RecBCD complex to expose ssDNA ends and load RecA, forming the nucleofilament that subsequently directs a homology search and strand invasion of dsDNA (Chen et al., 2008). Previously, it was shown that recA ${ }^{-}$ strains of E. coli join linear dsDNA with homologous overhangs in lysate more efficiently than their RecA-expressing counterparts. As $r e c B C D^{-}$strains have also been reported to direct accurate DNA end joining, ex vivo assembly reactions may involve mechanisms independent of homologous recombination machinery, perhaps by an alternative end-joining pathway (Chayot et al., 2010). We suspect that both ex vivo and in vivo DNA assembly is likely facilitated by multiple competing DNA repair mechanisms, but largely by RecBCD, RecJ, and RecQ.

The radio-resistant bacterium $D$. radiodurans has been shown to completely reassemble its genome from hundreds of radiationinduced DSBs in a matter of 3-4 h, using multiple copies of its genome as templates to facilitate accurate repair by homologous recombination (Cox and Battista, 2005). Intriguingly, D. 
radiodurans lacks any homolog to $\mathrm{Rec} B$ or $\mathrm{RecC}$, seemingly relying on the helicase, exonuclease, and RecA-loading activity of RecQ, RecJ, and the RecFOR system, respectively - although a RecAindependent system is known to exist as well (Daly and Minton, 1996; Jiao et al., 2012). Disappointingly, Dra consistently failed to yield transformants from ex vivo assembly reactions. Analysis of the reaction mixture by gel electrophoresis revealed high exonuclease activity indicated by the complete disappearance of the amplicon bands by $2 \mathrm{~h}$ (Figure S1 in Supplementary Material). More puzzling was the absence of background transformations by carryover plasmid DNA used as template in the PCR step, which indicated endonucleolytic activity by known and possibly unknown nucleases. While this constitutes a design consideration going forward, we hypothesize that the excessive exonuclease activity must be attenuated for $D$. radiodurans lysate to serve as an efficient catalyst for ex vivo DNA assembly.

The robust homologous recombination system and additional end-joining pathways found in S. cerevisiae make it a powerful host for in vivo DNA assembly. Indeed, TAR cloning in yeast has resulted in a number of successful large-scale feats of genetic engineering including construction of $\sim 454 \mathrm{kbp}$ of the high $\mathrm{G}+\mathrm{C}$ content genome of Synechococcus elongatus (Noskov et al., 2012). Therefore, it was surprising that Eco outperformed Sce in DNA end-joining reactions. It is possible that the buffer conditions that work well for Eco may not be optimal for the protein complexes in Sce, although we suspect there is a higher concentration of DNA repair proteins in Eco than Sce based on culture and lysis conditions. Therefore, DNA assembly with Sce may be limited by mass transport (not protein activity), which can be improved upon by synchronizing the cell cycle of the culture and/or harvesting more yeast cells.

While all organisms possess some ability to repair DSBs (Blackwood et al., 2013), we made several observations in the selection of organisms for ex vivo DNA assembly. Lysate derived from $D$. radiodurans was an exciting prospect for DNA assembly but clearly suffered from excessive nuclease activity. The cloning problems associated with endonuclease activity cannot be avoided without sequence design constraints (for sequence-specific endonucleases) or by generating a nuclease knockout strain, which may be exceedingly difficult in a genetically intractable organism such as $D$. radiodurans. Exonuclease activity is required for DNA end resection, but is a balancing act. We saw in Sce very little exonuclease activity, which preserves the regions of homology, but may not expose complementary overhangs. Conversely, extreme exonuclease activities, like that of Dra, may be resecting bi-directionally, deleting the necessary homologous regions. Again, knockouts of single-strand exonucleases implicated in deletion of exposed overhangs may greatly improve the efficiency of end joining (Dutra et al., 2007). Another strategy to improve efficiency may be to increase the lengths of homology on the fragments. Previous in vivo studies on single-strand annealing in S. cerevisiae showed an approximately linear dependence on homology up to $415 \mathrm{bp}$ with sequence homology as short as 29 bp used $0.2 \%$ of the time (Sugawara et al., 2000). In our work, we chose to use small overlapping regions because these can be embedded within short, inexpensive primers ( $<60$ mer). Haploid hosts, like E. coli, do not generally possess highly active end-joining mechanisms. Instead they rely on recA-dependent recombination to direct exposed ssDNA nucleofilaments toward homologous dsDNA. By using $r e c A^{-}$strains we postulate that our resected single-stranded ends are now permitted to anneal with other exposed complementary single-stranded ends rather than dsDNA templates. Directing recombination toward this single-strand annealing pathway may prove even more successful with microbes which more highly express these alternate end-joining mechanisms (Gupta et al., 2013). Using an ex vivo approach, the diversity of culturable microorganisms can be mined and quickly assayed for their ability to perform DNA end joining, exposing deeper insight into the mechanisms of DNA repair and new platforms for cloning.

The idea that genetic engineers can use native DNA repair mechanisms to build recombinant DNA molecules is not new. However, access to relatively cheap synthetic dsDNA has only recently become a reality. As DNA synthesis becomes less expensive, the majority of time and cost considerations will be spent on DNA assembly steps. Continued development of faster and cheaper DNA assembly methods, such as the ex vivo DNA assembly described here, will further accessibility to DNA-based studies and applications. Of course, there are limitations to ex vivo DNA assembly as with any approach. For example, all homology-based assembly methods are constrained by the fact that there must be overlapping homologous ends. While the overlapping lengths utilized here are easily designed and embedded in primers, it is impossible to generate genetic variants in which the diversity occurs within the overlapping region. In addition, ssDNA assembly appears to be better achieved by ISO assembly or polymerase chain assembly (PCA). Outside of these small design constraints, ex vivo DNA assembly should be a very useful method for genetic engineers and will hopefully contribute to lowering the monetary and time costs associated with building DNA.

\section{MATERIALS AND METHODS GENERATION OF DNA FRAGMENTS FOR EX VIVO DNA ASSEMBLY}

The DNA fragments used to demonstrate ex vivo DNA assembly were generated using standard PCR of parts of the following plasmids from the BioBricks registry: pSB1C3-J04450, pSB1C3K592009, and pSB1K3-J04450. Primers used in this study (Table S2 in Supplementary Material) were generated using the j5 automated DNA assembly software (Chen et al., 2012; Ham et al., 2012; Hillson et al., 2012). Amplicons were generated by $100 \mu \mathrm{L}$ PCR reactions with $\mathrm{Q} 5$ polymerase $(\mathrm{NEB})$ under standard reaction conditions. These reactions were cycled at $98^{\circ} \mathrm{C}$ for $30 \mathrm{~s} ; 98^{\circ} \mathrm{C}$ for $10 \mathrm{~s}$, $50^{\circ} \mathrm{C}$ for $15 \mathrm{~s}, 72^{\circ} \mathrm{C}$ for $25 \mathrm{~s}$ (repeated for 25 cycles); $72^{\circ} \mathrm{C}$ for $2: 00$. To purify these PCR reactions, samples were run on $1.0 \%$ agaroseTAE gels stained with GelGreen $\left(\right.$ Biotium $^{\mathrm{TM}}$ ). The gels were run at $100 \mathrm{~V}$ for $30 \mathrm{~min}$ and subsequently visualized under blue light. The gels showed no side product formation and bands were excised and isolated using ZymoClean ${ }^{\mathrm{TM}}$ Gel DNA Recovery Kit (Zymo Research).

\section{PREPARATION OF CELLULAR LYSATES}

Cellular lysates were prepared from the following strains: E. coli NEB10ß (NEB \#C3019), S. cerevisiae BY4741 and D. radiodurans R1 (ATCC ${ }^{\circledR}$ 13939). E. coli was grown in Terrific Broth with glycerol (Sigma) at $37^{\circ} \mathrm{C}$ with shaking at $250 \mathrm{rpm}$. D. radiodurans was 
grown in 123 TGY medium (5\% Tryptone, 5\% Yeast extract, $1 \%$ Glucose, $1 \%$ Potassium monophosphate) at $30^{\circ} \mathrm{C}$ and S. cerevisiae was grown with YPD media (Sigma) at $30^{\circ} \mathrm{C}$, both shaking at $250 \mathrm{rpm}$. The preparation of the bacterial (E. coli and D. radiodurans) and the $S$. cerevisiae lysates varied slightly: bacterial cultures were pelleted once the $\mathrm{OD}_{600 \mathrm{~nm}}$ reading was between 6.00 and 6.50 , while the yeast cultures were pelleted once they reached between 4.00 and $4.50 \mathrm{OD}_{600 \mathrm{~nm}}$. Volumes of $4-6 \mathrm{~mL}$ of culture were centrifuged at $13,200 \mathrm{rpm}$ at $4^{\circ} \mathrm{C}$ for $2 \mathrm{~min}$, washed with $1 \mathrm{~mL}$ of Milli-Q $\mathrm{H}_{2} \mathrm{O}$, centrifuged again and the wet pellet massed. 2X CelLytic B Lysis Reagent (Sigma) was added to the bacterial cell pellets at $3 \mu \mathrm{L} / \mathrm{mg}$ of cells. 1X CelLytic Y Lysis Reagent (Sigma) was added to the yeast pellets in the same ratio. After the addition of the lysis reagents, the cells were incubated at $37^{\circ} \mathrm{C}$ for $10 \mathrm{~min}$ shaking at $300 \mathrm{rpm}$. The lysed cells were centrifuged at 13,200 rpm for $15 \mathrm{~min}$ and a $20 \mu \mathrm{L}$ sample of the supernatant (lysate) was mixed with $20 \mu \mathrm{L}$ of $100 \%$ glycerol to yield $40 \mu \mathrm{L}$ aliquots. All lysate aliquots were stored at $-20^{\circ} \mathrm{C}$.

\section{DNA ASSEMBLY REACTIONS, AGAROSE GEL ANALYSES OF ASSEMBLED DNA, AND TRANSFORMATIONS}

Buffers for assembly reactions were prepared from $100 \times$ stock solutions. Stock solutions were as follows: $100 \mathrm{mM} \mathrm{NAD} \beta$, 100 mM ATP, 100 mM DTT, 1 M MgCl2 (Symington et al., 1983). Tris- $\mathrm{HCl}$ was added to the buffer to $500 \mathrm{mM}$ from a $1 \mathrm{M}$ stock solution. A typical assembly reaction would include $6 \mu \mathrm{L}$ of cellular lysate, $2 \mu \mathrm{L}$ of $10 \times$ buffer, $2 \mu \mathrm{L}$ of nuclease free water (Ambion ${ }^{\circledR}$ ), and $10 \mu \mathrm{L}$ of a DNA master mix. DNA master mixes contained all fragments needed for assembly and were formulated with $20 \mathrm{ng} / \mu \mathrm{L}$ of the backbone and 6:1 molar ratio of insert fragments

\section{REFERENCES}

Alieva, N. O., Konzen, K. A., Field, S. F., Meleshkevitch, E. A., Hunt, M. E., Beltran-Ramirez, V., et al. (2008). Diversity and evolution of coral fluorescent proteins. PLoS ONE 3:e2680. doi:10.1371/journal. pone. 0002680

Blackwood, J. K., Rzechorzek, N. J., Bray, S. M., Maman, J. D., Pellegrini, L., Robinson, N. P., et al. (2013). Endresection at DNA double-strand breaks in the three domains of life. Biochem. Soc. Trans. 41, 314-320. doi:10.1042/BST20120307

Chayot, R., Montagne, B., Mazel, D., and Ricchetti, M. (2010). An end-joining repair mechanism in Escherichia coli. Proc. Natl. Acad. Sci. U.S.A. 107, 2141-2146. doi:10.1073/pnas. 0906355107

Chen, J., Densmore, D., Ham, T. S., Keasling, J. D., and Hillson, N. J. (2012). DeviceEditor visual biological CAD canvas. J. Biol. Eng. 6, 1. doi:10.1186/1754-1611-6-1

Chen, Z., Yang, H., and Pavletich, N. P. (2008). Mechanism of homologous recombination from the RecA-ssDNA/dsDNA structures. Nature 453, 489-U3. doi:10.1038/nature06971
Cox, M. M., and Battista, J. R. (2005). Deinococcus radiodurans the consummate survivor. Nat. Rev. Microbiol. 3, 882-892. doi:10.1038/ nrmicro1264

Daly, M. J., and Minton, K. W. (1996). An alternative pathway of recombination of chromosomal fragments precedes recA-dependent recombination in the radioresistant bacterium Deinococcus radiodurans. J. Bacteriol. 178, 4461-4471.

Dutra, B. E., Sutera, V. A. J., and Lovett, S. T. (2007). RecA-independent recombination is efficient but limited by exonucleases. Proc. Natl. Acad. Sci. U.S.A. 104, 216-221. doi: 10.1073/pnas.0608293104

Gibson, D. G., Benders, G. A., Axelrod, K. C., Zaveri, J., Algire, M. A., Moodie, M., et al. (2008). Onestep assembly in yeast of 25 overlapping DNA fragments to form a complete synthetic Mycoplasma genitalium genome. Proc. Natl. Acad. Sci. U.S.A. 105, 20404-20409. doi:10. 1073/pnas.0811011106

Gibson, D. G., Young, L., Chuang, R. Y., Venter, J. C., Hutchison, C. A. 3rd, and Smith, H. O. (2009). Enzymatic assembly of DNA molecules

to the backbone. Gel analysis was performed using 1.0-1.2\% agarose-TAE gels containing GelRed (Biotium) as the staining agent. All analytical gels were run at $100 \mathrm{~V}$ for 30-50 min and visualized with a Molecular Imager ${ }^{\circledR}$ Gel Doc ${ }^{\mathrm{TM}} \mathrm{XR}+$ Imaging System with Image Lab ${ }^{\mathrm{TM}} \mathrm{v} 4.0$ software (Bio-Rad). Transformations were performed using chemically competent E. coli NEB10 $\beta$ (NEB) according to manufacturer's recommendations. Briefly, $2 \mu \mathrm{L}$ of reaction mixture (from ex vivo assemblies) or diluted DNA master mix (for in vivo assembly) were added to each transformation, these were incubated for $30 \mathrm{~min}$ on ice, heat shocked at $42^{\circ} \mathrm{C}$, recovered in $950 \mu \mathrm{L} \mathrm{SOC}$ at $37^{\circ} \mathrm{C}$ for $60 \mathrm{~min}$ and $50 \mu \mathrm{L}$ of culture was spread onto agar plates containing the appropriate antibiotic.

\section{AUTHOR CONTRIBUTIONS}

George H. McArthur and Adam B. Fisher designed the experiments, which were carried out in the laboratory of Stephen S. Fong. Adam B. Fisher performed the experiments with Zachary B. Canfield and Laura C. Hayward. George H. McArthur, Adam B. Fisher, and Stephen S. Fong interpreted the data and wrote the manuscript. All authors discussed results and commented on the manuscript.

\section{ACKNOWLEDGMENTS}

George H. McArthur acknowledges the generous support of a VCU Graduate School Dissertation Assistantship (2012-2013).

\section{SUPPLEMENTARY MATERIAL}

The Supplementary Material for this article can be found online at http://www.frontiersin.org/Journal/10.3389/fbioe.2013.00012/ abstract

up to several hundred kilobases. Nat. Methods 6, 343-345. doi:10.1038/ nmeth. 1318

Gupta, R., Ryzhikov, M., Koroleva, O., Unciuleac, M., Shuman, S., Korolev, S., et al. (2013). A dual role for mycobacterial $\mathrm{RecO}$ in RecAdependent homologous recombination and RecA-independent singlestrand annealing. Nucleic Acids Res. 41,2284-2295. doi:10.1093/nar/ gks1298

Ham, T. S., Dmytriv, Z., Plahar, H. Chen, J., Hillson, N. J., and Keasling, J. D. (2012). Design, implementation and practice of JBEI-ICE: an open source biological part registry platform and tools. Nucleic Acids Res. 40, e141-e141. doi:10.1093/nar/ gks531

Hartley, J. L., Temple, G. F., and Brasch, M. A. (2000). DNA cloning using in vitro site-specific recombination. Genome Res. 10, 1788-1795. doi:10. 1101/gr.143000

Hillson, N. J., Rosengarten, R. D., and Keasling, J. D. (2012). j5 DNA assembly design automation software. ACS Synth. Biol. 1, 14-21. doi:10.1021/ sb2000116

Jiao, J., Wang, L., Xia, W., Li, M., Sun, H. $\mathrm{Xu}, \mathrm{G}$., et al. (2012). Function and biochemical characterization of RecJ in Deinococcus radiodurans. DNA Repair (Amst.) 11, 349-356. doi:10. 1016/j.dnarep.2011.11.008

Li, M. Z., and Elledge, S. J. (2007). Harnessing homologous recombination in vitro to generate recombinant DNA via SLIC. Nat. Methods 4, 251-256. doi:10.1038/nmeth1010

Ma, H., Kunes, S., Schatz, P. J., and Botstein, D. (2002). Plasmid construction by homologous recombination in yeast. Gene 58, 201-216. doi:10.1016/03781119(87)90376-3

Noskov, V. N., Karas, B. J., Young, L., Chuang, R. Y., Gibson, D. G., Lin, Y. C., et al. (2012). Assembly of large, high $\mathrm{G}+\mathrm{C}$ bacterial DNA fragments in yeast. ACS Synth. Biol. 1, 267-273. doi:10.1021/sb3000194

Polisson, C., and Morgan, R. D. (1989). DrdI, a unique restriction endonuclease from Deinococcus radiodurans which recognizes 5'GACN6GTC3'. Nucleic Acids Res. 17, 3316. doi:10. 1093/nar/17.8.3316

Quan, J., and Tian, J. (2009). Circular polymerase extension cloning of complex gene libraries and pathways. PLOS ONE 4:e6441. doi:10. 1371/journal.pone.0006441 
Quan, J., and Tian, J. (2011). Circular polymerase extension cloning for high-throughput cloning of complex and combinatorial DNA libraries. Nat. Protoc. 6, 242-251. doi:10.1038/nprot.2010. 181

Smith, H. O., Hutchison, C. A., Venter, J. C., Gibson, D. G., and Merryman, C. (2010). Chemical synthesis of the mouse mitochondrial genome. Nat. Chem. Biol. 7, 901-903. doi:10.1038/ nmeth.1515

Sugawara, N., Ira, G., and Haber, J. E. (2000). DNA length dependence of the single-strand annealing pathway and the role of Saccharomyces cerevisiae RAD59 in double-strand break repair. Mol. Cell. Biol. 20, 5300-5309.
doi:10.1128/MCB.20.14.5300-5309. 2000

Symington, L. S., Fogarty, L. M., and Kolodner, R. (1983). Geneticrecombination of homologous plasmids catalyzed by cell-free-extracts of Saccharomyces Cerevisiae. Cell 35, 805-813. doi:10.1016/00928674(83)90113-7

Taylor, A. F., and Smith, G. R. (1995). Strand specificity of nicking of DNA at chi sites by RecBCD enzyme. Modulation by ATP and magnesium levels. J. Biol. Chem. 270, 24459-24467. doi:10.1074/jbc.270. 41.24459

Wilson, J. E., and Chin, A. (1991). Chelation of divalent cations by ATP, studied by titration calorimetry. Anal. Biochem. 193,
16-19. doi:10.1016/0003-2697(91) 90036-S

Zhang, Y., Werling, U., and Edelmann, W. (2012). SLiCE: a novel bacterial cell extract-based DNA cloning method. Nucleic Acids Res. 40, e55. doi:10.1093/nar/gkr1288

Conflict of Interest Statement: The authors declare that the research was conducted in the absence of any commercial or financial relationships that could be construed as a potential conflict of interest.

Received: 06 September 2013; accepted: 06 October 2013; published online: 21 October 2013.

Citation: Fisher AB, Canfield ZB, Hayward LC, Fong SS and McArthur GH
IV (2013) Ex vivo DNA assembly. Front. Bioeng. Biotechnol. 1:12. doi: 10.3389/fbioe.2013.00012

This article was submitted to Synthetic Biology, a section of the journal Frontiers in Bioengineering and Biotechnology. Copyright () 2013 Fisher, Canfield, Hayward, Fong and McArthur IV. This is an open-access article distributed under the terms of the Creative Commons Attribution License (CC BY). The use, distribution or reproduction in other forums is permitted, provided the original author(s) or licensor are credited and that the original publication in this journal is cited, in accordance with accepted academic practice. No use, distribution or reproduction is permitted which does not comply with these terms. 